\title{
FLUID FLOW ANALYSIS OVERANACRYLINO NITRILE BUTADIENE STYRENE BASED STRUCTURE AND THEIR COMPREHENSIVE FABRICATION
}

\author{
RAGHAVENDRA PAI K \& SHARATH CHANDRA H.S
}

Assistant Professor, Department of Mechanical Engineering, NMAM Institute of technology, Nitte, India

\begin{abstract}
An evolution to the everyday design had been bought by the design material that is worn, which was adopted for the first time ever by Acrylino nitrile butadiene styrene (ABS), a material with a thermal co efficient of 12x10-5and has a density of $0.9 \mathrm{~g} / \mathrm{cm} 3$ to $1.53 \mathrm{~g} / \mathrm{cm} 3$.The reason why this material was chosen is that, on understanding the more common materials such as stainless steel, aluminum, tungsten, it was clear that they lacked he need properties in one way or the other. The objectives to be looked over were to reduce the drag component, increasing the component of lift and also reducing turbulence. The daily deciphering of different kinds of materials is helping the world move onto bigger objectives which not only include a better and more reliable technology but even on the economical, feasible and other social factors too. The growth for material science into the future is tremendous.

KEYWORDS: ABS; Composite; 3-D Printing
\end{abstract}

Received: Jun 10, 2020; Accepted: Jun 30, 2020; Published: Jul 27, 2020; Paper Id.: IJMPERDJUN2020477

\section{INTRODUCTION}

Science and its very idea are the most exploited aspects of this world, making the most blossoming changes and progress. On a parallel stretch, the evolution of technology has always been the greatest gifts to mankind in helping mobilize science from mind and paper to the most flexible technology the world, would dawn to see. The Aviation Industry is a concentrated sector that has become subject to tremendous growth over the last century. It has witnessed the birth, the evolution and the never-ending ideological change to the dream of humans wanting to fly high above the clouds. However, with the constant change of technology, it has become more demanding and understanding that this technology needs to be tested, in order to be deciphered before they are to be put on a flying pinnacle of change. This was a need that always existed, so as to ensure that the physical numbers and formulas did not have a loophole in them that would cause unexpected and horrific complications in the broader and working structure of their practical application.

This evaluating demand started to arise as there was a rapid increase in the number of aviation fatalities in the budding stage of the industry. Many of the results could always be traced back due to the lack in the tolerability of the numbers that ran for the operating structures which had their own ceiling, beyond which tests were never considered or were not applicable. Computational fluid dynamics, a modern-day marvel in regard to being the most adoptive fusion between working science and relentless technology, has been the biggest grace to aviation in recent times. This can be evidently noted in the high degree of fluid motion that can be studied on this platform. Since the flight of Kitty Hawk [1] on the $17^{\text {th }}$ of December, it has been of pivotal importance to build more strength enduring and resilient aircraft. 
With the passing of time, aircrafts went from being the simple wood works of flight to being coupled with the industrial explosion the world was witnessing. The materials that grew onto an aircraft bought into the limelight, the understanding of the potential that this industry held and that witnessed more research and deliberate understanding. As referred earlier, wood was the very original element which was used for constructing an aircraft. Wood was then considered as the go to material to factor in a good strength to weight ratio Gaitondeet. al [2]. This proved to be of critical importance in terms of design because the designers were well aware of wanting to be sending into the air, a light an aircraft as possible. This need for design can be wired down to satisfying the math which would go into engineering of the forces which would sustain flight for the aircraft in air Hocheng [3].The application of different materials bought to notice how the aerodynamics of the aircraft were responding depending on the different working figured. With the passing of time brought into consideration the flexibility of using more advanced materials such as steel and others under similar groups which showcased properties that were in favor of the aerodynamics to a flying structure Koplev [4]. However, even when the materials are significantly very strong, they have peak values beyond which they cannot and should not be worked as that would lead to the growth of unnecessary stresses and loads on the flying structure, which if pushed to greater degrees can prove to be very dangerous.

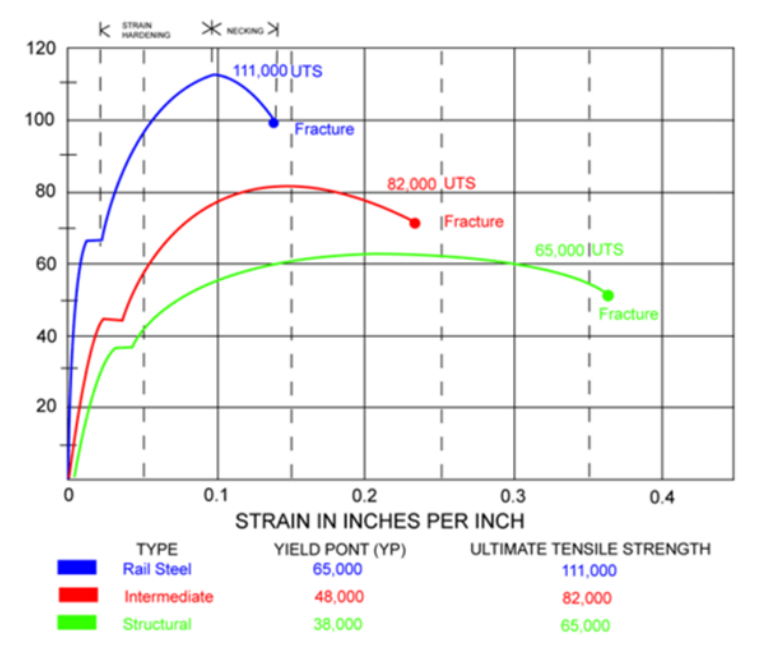

Figure 1: A Graph Indicating the Strength Response of Various Kinds of Steel.

Materials, over time started gaining significant advance, crafting out several prospects which were promising. Over the initial few decades after the flight of Kitty Hawk, the wood and fabric construction of the aircraft made the smartest switch to the utility of metals Mukhyopadhyay [5]. The reason can be simply traced to the significant rise in the mechanical properties. Wood, is designated to be having an ultimate tensile strength of $40 \mathrm{MPa}$, but the everyday stainless steel on the other hand had a $505 \mathrm{MPa}$. This simply underlines as to how different the material properties can be and how critical they will be in design Barbero [6]. A material well recognized as one of the strongest materials in the world, Titanium, is said to be used on an aircraft as well, but its commercial viability was very restrained because of the economics that were related to it. In the year 1928, one of the very first passenger flights become part of the trident leading group, to be using aluminum in their construction. Aluminum ( $\mathrm{Al}$ ), was a choice of construction that would have chosen to be around for the over the next few decades all together. It was mostly recognized for its high strength to weight ratio, which proved critical as that would provide a light fuselage and frame but also accompanied the ability to carry far heavier weights, much like how the simple work of this world allows an ant to carry ten times its own weight. An interesting 
character of this material is also that, it develops an oxide layer when brought into contact with air which prevents further oxidation from occurring Faraz et.al [7]. The ever-changing hands of the clock however brought forth newer and far resilient materials. With the dawn of the modern century, composite materials came into the industry and started making its way to slowly consume away the use of Aluminum. The focal center to these composites is that they help break the existing values set for various aerodynamic characters to an aircraft. Boeing, a global leader at aircraft manufacturing had used composites in their infancy projects by the incorporation of fiberglass. But as innovative as that might've proved, time had its own limitations to that point. Presently operating in the industry are the Boeing 787 and the Airbus A 350 series which have embraced the composite world very well and as for the future both Boeing and Airbus have several proposed projects who are seeing the dawn as they have inculcated very strategic use of composite structures.

\section{EXPERIMENTAL PROCEDURE}

The core idea of the experiment being conducted is to understand the application of aerodynamic principles onto a structure other than an aircraft and see how very healthy the application could turn out to be. The same aerodynamic properties are studied, as what would have been for the case of an aircraft, but the only difference for a vehicle is that it's a more grounded structure which makes it a dire necessity to understand how different the properties could be and where are the significant changes that need to be applied. The experiment carried out had been done keeping in mind a few clear sets of objectives:

- To provide a design to the structure such that it enables a downshifting of the drag component that would be developed as the structure moves forward.

- Pushing the magnitude of the lift component above its presently performing value so as to achieve faster speeds.

- The element of turbulence is of primary caution and concern to the designers and so, the elimination or reduction of the turbulence as far as possible should tried to be attained.

The primary focus of fabrication originally lied on the material which would be adopted for the construction of the aero foil. The material selection was important to feed particular data to the software's. This project finalized on the material known as Acrylonitrile butadiene styrene, called as ABS in short for their fabricating purposes. It was known that in the temperature range of -20 to 80 degree Celsius the material worked very well and added to that, it is economical and hence can be cheerfully adopted. In regard of 3-D printing also, this material proved to be healthy enough.

ABS had a lot of significant properties which were clubbed into it and all put together proved to be of huge importance, scientifically, but also economically. The material showcased a very elastic impact resistance allowing it to be able to endure a high degree of impact and also its electrical insulation property gave it the promising edge against the lighting strikes which the aircraft would have to endure when flying through unpredictable weather.

The design phase helped draw a negotiation to the kind of structure that would be adopted. Different designs were interpreted at first, but the initial designs did not prove to be numerically appropriate enough and demanded the iterative shaping of a new design and a design was finally adhered to. The design model was created by the aid of the CATIA and UG-NX softwares. Upon the application of the needed parameters to the model, the mesh was tested and it resulted in an understanding as figuratively described below: 


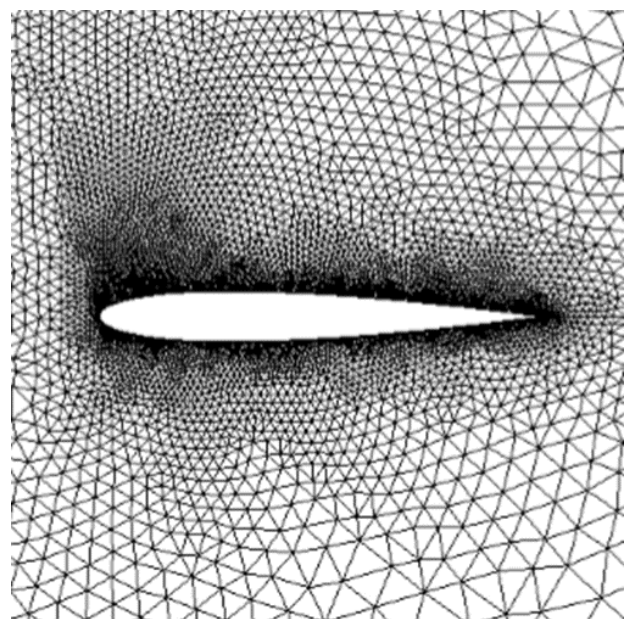

Figure 2: This Image Above Depicts to the Large Number of Nodes that were Considered for this Particular Solution.

The conditions that were applied to the mesh were that, across the computational domain a velocity of $30 \mathrm{~m} / \mathrm{s}$ was applied to the inlet. The outlet conditions were maintained at atmospheric with one bar of pressure and the corresponding temperature. On solving the shear stress model, a definitive understanding was grown of how the turbulent shear stress would be transported and that helped to draw highly accurate results. Once the aerofoil design was completed, it was then made to undergo various tests so as to study its aerodynamic characteristics. The tests were a success as the result produced were outstandingly promising which provided enough batter to be believed in to proceed with the construction models and their further understanding. The table and plot below describe their results:

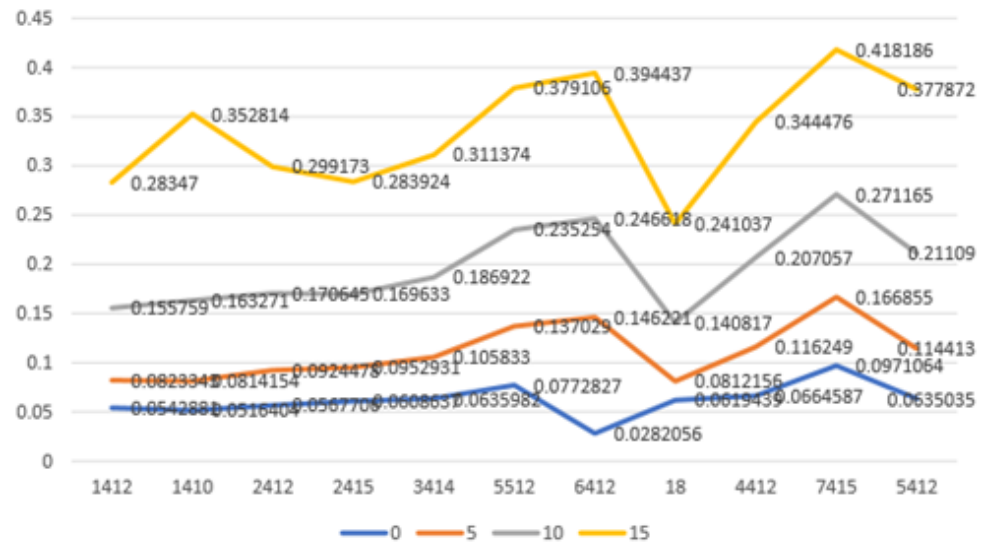

Figure 3: The Experimental Numbers being Plotted on a Working Graph.

Since the numbers behind the experiment did prove to fit into the needed spaces, further understanding was demanded from the structural fabrication point of view. The addition of the concept of end plates helped realize that the sudden drop of air as it travels over the aerofoil section can be changed. Their addition helps to bring an uniform flow of air over the aerofoil and helps engage in better aerodynamic strength which further adds to the foundation of their construction. Once the end plates were constructed onto the structure, it was checked on several rounds to ensure that the structure would still hold good in operations.

At this point of time, the needed observations were made and after several corrections that were bought to the designing, the final shape was given to the structures and then were all assembled virtually to have an apprehension of the size and shape of the cumulative structure. This apprehension had resulted in the following structure 


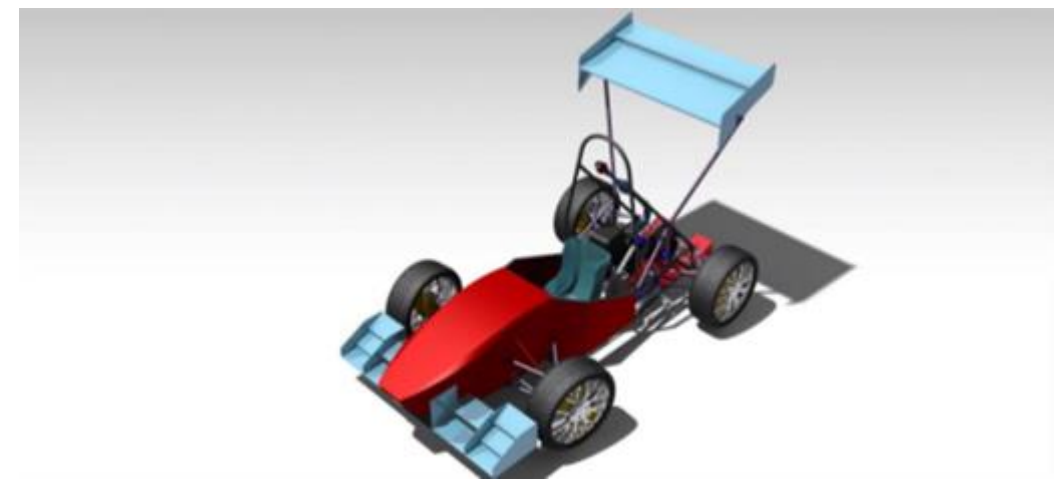

Figure 4: When the Various Components are put together after Testing, the Vehicle would look Approximately as Depicted.

The use of 3D printing was very critical in the fabrication of vortex generators which were used so as to help generate better flow of the air towards the trailing edges, further cementing the want to be able to reduce the amount of turbulence that would have otherwise been generated and further credibility has to be pinned to the software's which helped to have a clearer and more deeper understanding of the fluid flow over the structure.

\section{RESULTS}

The tests resulted in a flow as depicted in Fig 6 As evidently seen, the flow has been more enhanced by the structural modification that's been inculcated and this would promise better aerodynamic lift and would reduce the drag component and hence, satisfying the founding objectives of this particular project.

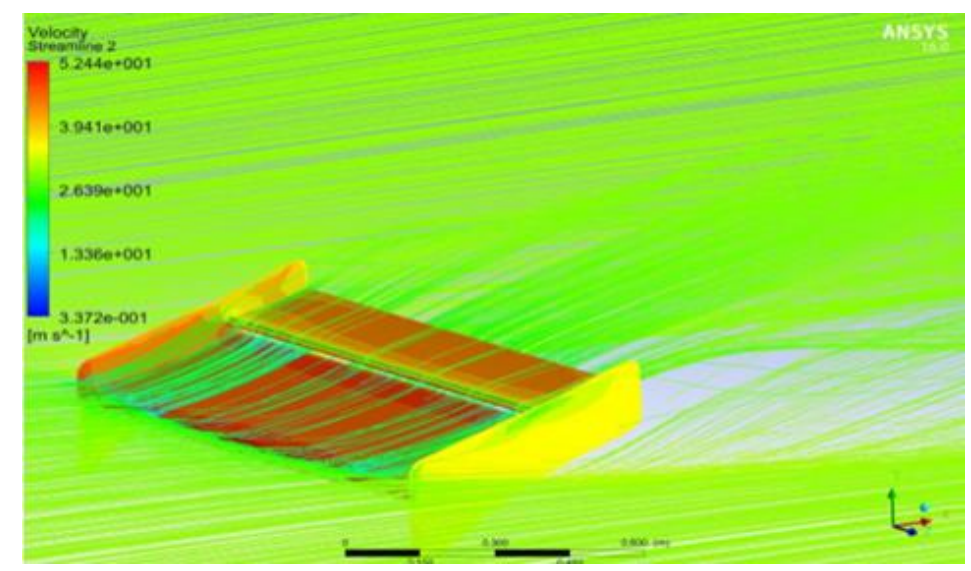

Figure 5: The Application of the Air Flow Data Over the End Plate Structure would look like this.

\section{DISCUSSION}

The attained results were only deciphered after having a look to how the software would present data and what have been the results in the relevant field as well. This provided a strong foundation to work on as the number attained could then be cross checked so as to know, if a degree of improvement has been achieved or not.

\section{CONCLUSIONS}

The idea of inculcation of aerodynamics to grounded structures is one that is not very new to the world, but one that has been only exploited with a limit. The understanding of the idea that, not just aerodynamics but knowing the aircraft material has become of pivotal importance. The numbers attained over the iterative experiments have been promising and 
their near to perfect fabrication has showcased their applicative possibilities also with the aid of different materials. The few keen objectives that which were aimed to be achieved such as better lift, lower drag and reduction of the turbulence factor could be achieved with the acrylino nitrile butadiene styrene far above expected and the results prove strong enough for further research and better application to the future, ensuring that the composite material sector has a lot of growth waiting to happen.

\section{REFERENCES}

1. Soutis, C., "Fibre reinforced composite in aircraft construction", ProgrAerosp Sci, Vol. 41, pp. 143-51, 2005.

2. Gaitonde, V.N., Karnik, S.R., Rubio, J.C., Correia, A.E., Abrao, A.M., and Davim, J.P., "Analysis of parametric influence on delamination in high-speed drilling of carbon fiber reinforced plastic composites”, J Mater Process Technol, Vol. 203, pp. 431-9, 2008.

3. Hocheng, H., Tsao, C.C., "Effects of special drill bits on drilling-induced delamination of composite materials", Int J Mach Tools Manuf, Vol. 46, pp. 1403-16, 2006.

4. Koplev, A., "Cutting of CFRP with single edge tools", Proceed Adv Compos Mater, pp. 1597-605, 1980.

5. MadhujitMukhyopadhyay, "Mechanics of composite materials and structures", 2nd ed. Hyderabad: India; 2004.

6. Barbero, E.J., "Introduction to composite materials design", 2nd ed. London: New York; 2008.

7. Faraz, A., Biermann, D., Weinert, K., "Cutting edge rounding: an innovative tool wear criterion in drilling CFRP composite laminates”, Int J Mach Tools Manuf, Vol. 49, pp. 1185-96, 2009.

8. Singh, Ddev, and Avala Raji Reddy. "Characterization of Additive Manufactured ABS and Natural ABS Specimens." International Journal of Mechanical and Production Engineering Research and Development (IJMPERD) 8.3 (2018):717724.

9. Pittala, Suresh, and T. Diriba. "Computational Fluid Dynamics Analysis of Impeller Design for a Pump." International Journal of Mechanical Engineering (IJME) 5.4 (2016): 63-74.

10. Bhagwat, Shreyas V., Vishal V. Shukla, and Mohan G. Trivedi. "An Engineering Investigation of Bio-Polymers." International Journal of Mechanical and Production Engineering Research and Development (IJMPERD) 9. Special Issue (2019):348-355.

11. Equbal, Azhar, et al. "Optimization of process parameters of FDM parts for minimiizing its dimensional inaccuracy." International Journal of Mechanical and Production Engineering Research and Development (IJMPERD) 7.2 (2017): 57-66. 